\title{
PROMOÇÕES CULTURAIS
}

Aula inaugural do Curso de Graduação em Direito (ano de 1990), proferida pelo Ministro José Rezeck, sobre o tema "Sistema Eleitoral".

Aula inaugural do Curso de Graduação em Direito (ano de 1991), proferida pelo Procurador Geral da República, Dr. Aristides Junqueira Alvarenga, sobre o tema: "O Papel do Ministério Público Federal na Nova Constituição".

Semana do Calouro, com a participação dos seguintes palestrantes: Prof. Alfredo de Assis Gonçalves Neto, Diretor do Setor de Ciências Jurídicas da UFPR; Prof. Ivan Guérios Curi, Coordenador do Curso de Graduação em Direito da UFPR; Prof. Carlos Alberto Faraco, Reitor da UFPR; Roberto Freire e José Augusto Albuquerque.

Semana do Calouro, com a participação dos seguintes palestrantes: Dr. Francisco de Paula Xavier Neto, Presidente da Associação dos Magistrados do Paraná; Dr. Sílvio Rodrigues, Professor da Faculdade de Direito da Universidade de São Paulo; Dr. Alfredo de Assis Gonçalves Neto, Diretor do Setor de Ciências Jurídicas da UFPR e Prof. Carlos Alberto Faraco, Reitor da UFPR.

Curso de Especialização em Ciências Penais, com a participação dos seguintes professores: Dr. Luiz Alberto Warat, Dr. Rogério Lauria Tucci, Dr. Vladimir Passos de Freitas, Dr. João Marcelo de Araújo Júnior, Dr. Nilo B. de Brum, Dra. Ela Wieko Volkmer de Castilho e Dr. Técio Sampaio Ferraz Júnior.

Semana de Estudos de Direito Público, com a participação dos seguintes palestrantes: Prof. Clèmerson Merlin Clève (As medidas provisórias na Constituição Federal); Prof. Jacinto Nel- 
son de Miranda Coutinho (Princípio da oficialidade no processo penal); Prof. Romeu Felipe Bacellar Filho (Responsabilidade Civil no Estado) e Prof. Manoel Caetano Ferreira Filho (Dinâmica do processo - análise crítica).

Curso de Direito Ambiental, sobre o tema: "Estudo de impacto ambiental", com a seguinte programação: Considerações sobre o estudo de impacto ambiental e sua aplicação no Estado de São Paulo (Édis Milaré, Procurador de Justiça e Chefe da Curadoria do Meio Ambiente de São Paulo); Aspectos gerais do Estudo de impacto ambiental (Eliseu Moraes Corrêa, Mestre em Direito pela UFPR, Professor da Faculdade de Direito de Curitiba e Procurador do ITCF); O passivo ambiental da empresa e o estudo de impacto ambiental (Jair Lima Gevaerd Filho, Especializado em Direito do Desenvolvimento pelo IDLI, Roma, Procurador do Estado do Paraná e Professor da Faculdade de Direito da UFPR); Estudo de impacto ambiental e participação popular (Maude Nancy Joslim Motta, Procuradora do ITCF) e Manoel Eduardo Camargo e Gomes (Assessor Jurídico do Tribunal de Alçada do Paraná e Mestrando em Direito pela UFSC); Considerações sobre o estudo de impacto ambiental e sua aplicação no Estado do Rio de Janeiro (Francisco Sampaio, Procurador do Estado do Rio de Janeiro).

\section{Cursos de Extensão Universitária:}

Segunda Semana de Atualização em Processo Civil, com a seguinte programação: Aspectos do agravo de instrumento (Prof. ${ }^{a}$ Tereza Celina Alvim Pinto); A nova sistemática dos recursos especiais (Prof. Nelson Luiz Pinto); Requisitos da sentença (Prof. Egas Dirceu Moniz de Aragão); Painel: Intervenção de terceiros (Profs. Ivan Ordine Righi, Alcides Alberto Munhoz da Cunha, Newton Álvaro da Luz, Manoel Caetano Ferreira Filho e Edson Ribas Malachini); Execução por quantia certa - aspectos polêmicos da execução por título executivo extrajudicial (Prof. Donaldo Armelin).

Direito Constitucional Positivo, sob a coordenação do Prof. Clèmerson Merlin Clève, com a participação dos seguintes palestrantes: Prof. Ivan Guérios Curi, Prof. José Eduardo Soares de Camargo, Prof. ${ }^{a}$ Regina de Macedo Nery Ferrari, Prof. Clè- 
merson Merlin Clève, Prof. Manoel Caetano Ferreira Filho, Prof. Jacinto Nelson de Miranda Coutinho, Prof. Sebastião Antunes Furtado, Prof. Luiz Guilherme Marinoni e Prof. Alcides Alberto Munhoz da Cunha.

Técnicas de Estudos e Metodologia do Trabalho Científico aplicadas ao Direito, sob a coordenação da Prof. Maria de Lourdes Seraphico Peixoto da Silva.

Conferências e palestrus proferidas por professores visitantes:

A estrutura do Direito Penal Polonês. Prof. Marian Cieslak, Catedrático de Direito Penal da Universidade de Gdanski-Polônia e Presidente do Grupo Polonês da Associação Internacional de Direito Penal.

A utilização informática de obras intelectuais. Prof. José de Oliveira Ascenção, Catedrático da Universidade de Lisboa.

Crítica à dogmática jurídica e hermenêutica jurídica. Dr. Plauto Faraco de Azevedo, da Universidade Federal do Rio Grande do Sul.

Princípios fundamentais do processo. Dr. Ovídio Baptista da Silva, Professor Titular da Faculdade de Direito da Universidade Federal do Rio Grande do Sul.

A criminalidade econômica. Dr. João Marcelo de Araújo Filho, Professor Titular da Universidade Federal do Río de Janeiro e Secretário da Associação Internacional de Direito Penal.

Direito Constitucional e constitucionalidade das leis no Japão após a segunda guerra mundial. Dr. Satoru Osanai, Professor Titular da Faculdade de Direito da Universidade dè Chûo-Japão.

Direito de Família. Dr. Sebastião Taffaro, Professor Titular da Universidade de Bari-Itália.

Teoria Geral da parte especial do Código Penal. Dr. Jair Leonardo Lopes, Professor Titular de Direito Penal da Universidade Federal de Minas Gerais.

Teoria Geral do Processo Penal. Dr. Rogério Lauria Tucci, Professor Titular de Direito Processual Penal da Universidade de São Paulo. 
Existe Justiça absoluta? Dr. Valentin Petev. Professor da Universidade de Münster-Alemanha.

Da noção de sujeito: uma visão a partir do direito e da psicanálise. Dr. Agostinho Ramalho Marques Neto, Professor da Faculdade de Direito da Universidade Federal do Maranhão. 